\title{
Intersection of neighborhood dynamics and socioeconomic status in small-area walkability: the Heart Healthy Hoods project
}

Pedro Gullón ${ }^{1,2 \dagger}$, Usama Bilal ${ }^{1,3 \dagger}$, Alba Cebrecos ${ }^{1,4}$, Hannah M. Badland ${ }^{5}$, Iñaki Galán ${ }^{6}$ and Manuel Franco ${ }^{1,3^{*}}$

\begin{abstract}
Background: Previous studies found a complex relationship between area-level socioeconomic status (SES) and walkability. These studies did not include neighborhood dynamics. Our aim was to study the association between area-level SES and walkability in the city of Madrid (Spain) evaluating the potential effect modification of neighborhood dynamics.
\end{abstract}

Methods: All census sections of the city of Madrid $(n=2415)$ were included. Area-level SES was measured using a composite index of 7 indicators in 4 domains (education, wealth, occupation and living conditions). Two neighborhood dynamics factors were computed: gentrification, proxied by change in education levels in the previous 10 years, and neighborhood age, proxied by median year of construction of housing units in the area. Walkability was measured using a composite index of 4 indicators (Residential Density, Population Density, Retail Destinations and Street Connectivity). We modeled the association using linear mixed models with random intercepts.

Results: Area-level SES and walkability were inversely and significantly associated. Areas with lower SES showed the highest walkability. This pattern did not hold for areas with an increase in education level, where the association was flat (no decrease in walkability with higher SES). Moreover, the association was attenuated in newly built areas: the association was stronger in areas built before 1975, weaker in areas built between 1975 and 1990 and flat in areas built from 1990 on.

Conclusion: Areas with higher neighborhood socioeconomic status had lower walkability in Madrid. This disadvantage in walkability was not present in recently built or gentrified areas.

Keywords: Physical activity, Neighborhood/pace, Urbanisation, GIS

\section{Background}

A quarter of the population in Europe is estimated to be physically inactive [1]. Reducing physical inactivity is one of the key targets to control non-communicable diseases [2] as it is estimated to be responsible for $6-10 \%$ of the burden of major non-communicable diseases worldwide [3]. Cities, due to the possibility of population approaches $[4,5]$, represent an opportunity for public health interventions on physical inactivity $[6,7]$.

\footnotetext{
*Correspondence: mfranco@uah.es

${ }^{\dagger}$ Pedro Gullón and Usama Bilal contributed equally to this work

1 Social and Cardiovascular Epidemiology Research Group, School

of Medicine, University of Alcalá, Alcalá de Henares, Madrid 28871, Spain

Full list of author information is available at the end of the article
}

Walkable neighborhoods (dense, compact, with availability of walking destinations) are associated with improved walking behaviors [8-10]. In addition, physical inactivity follows a social gradient, with more disadvantaged populations having a higher prevalence of physical inactivity [11-13]. Thus, the interaction between urban form (defined as physical form of the city [14]) and social disadvantage could provide insights on how socio-spatial inequalities in physical activity are shaped [15]. Previous evidence suggests that the relationship between Neighborhood Socioeconomic Status (SES) and neighborhood walkability may be complex [16]. In particular, previous research has found that lower SES neighborhoods are more walkable (measured 
using objective measures) [16-19], while on the other hand residents of more deprived neighborhoods report worst aesthetics and safety of their neighborhoods [20,21], which may also be important contributors to walking behaviors. However, most of the studies looking at the relationship between social and urban form have been conducted mainly in the US and Australia, where the shape of urban environments [22] and socioeconomic segregation processes [23] differs widely from European cities.

Moreover, neighborhoods and cities are not static entities, they are dynamic in its form and composition [24]. Urban form changes at a slower pace than social composition, as citizens might move following a social gradient in response to changes in the housing prices market [25]. At the same time, urban form tends to change at a slow pace, given its constrains in some parts of the city (e.g. inner old city). In order to understand the socio-spatial inequalities in walkability there is a need to incorporate variables that can help to understand the dynamics and the history of the city. In our study, we try to encompass this challenge by incorporating variables of change in social composition and the age of the neighborhood.

The Heart Healthy Hoods project (HHH) aims to study how urban environment relates to cardiovascular health of Madrid's residents [6, 26, 27]. Within this project, some measures of physical activity environment have been tested [28]. Taking all the above into consideration, our aim was to evaluate the association between small area-level socioeconomic status and walkability in the city of Madrid (Spain) and to evaluate the potential effect modification by indicators of neighborhood dynamics (gentrification and neighborhood age).

\section{Methods}

\section{Study setting}

We conducted our study in the City of Madrid, Spain. In 2014, Madrid was divided into 21 districts that housed 128 neighborhoods, that were further divided into 2415 census sections [29]. The Census Section was the unit for all the analysis as this is the smallest area for which census and other relevant data were available. Census Sections had resident populations of between 1000 and 1500 people. Madrid's socio-spatial configuration is one of the most segregated in Europe [30]. As most of European cities, it has a historic city center, and neighborhoods separated from it by an orbital motorway [31]. Since the 60s, it has experienced a huge economic and population growth due to the industrialization of some parts of the region and the migration from rural areas. Higher social class tend to accumulate in the northern part of the city [30].

\section{Area socioeconomic status}

The main exposure of this study was a composite SES index made of 7 indicators. These were: (1) Low education (defined as \% people above 25 years of age with primary studies or below), (2) High education (defined as \% people above 25 years of age with university education or above), (3) Part-time employment (\% workers in parttime jobs), (4) Temporary employment (\% workers in temporary jobs), (5) Manual occupational class (\% workers in manual or unqualified jobs), (6) Average housing prices (per sq. m), and (7) Unemployment rate. These indicators were selected based in the 4 domains present in the Spanish Commission to Reduce Health Inequalities [32] (education, wealth, occupation and living conditions). Using this framework, the SOPHIE project have investigated the effect of structural policies on health inequalities [33]. Indicator data were obtained from the Padrón (a continuous and universal census collected for administrative purposes), the social security and employment services registries and the IDEALISTA report (a report from a large real estate corporation in Spain). All data were available for the year 2014. Table 1 (and Additional file 1) contains more details on the operationalization of indicators.

To create the SES index, we constructed a weighted index from the variables described above. For this we centered (to the mean) and scaled (by the standard deviation) all selected variables. We then weighted the four domains equally ( 0.25 per domain) and weighted all variables within each domain equally (e.g.: overall, each education variable has a weight of $0.25 \times 0.5=0.125)$. We then averaged all standardized variables to obtain the SES Index. We compared this index to a score obtained using the principal component of a Principal Component Analysis and found a Pearson correlation of 0.997 between them.

\section{Neighborhood dynamics}

For neighborhood dynamics, we selected 2 indicators: gentrification and neighborhood age. An indicator for gentrification was obtained by ranking all census sections in 2005 and in 2014 in terms of \% residents with high education (university education or above) and computing the change in rank from 2005 to 2014, where we defined a gentrified neighborhood as those in the top 95\% percentile of rank change. Neighborhood age was proxied by the median year of construction of all housing units in the census section, obtained from the Cadastre (Catastro, a universal tax registry of all housing units). We created three categories: up to 1985, from 1985 to 1997, from 1997 onwards. These categories were created based on the time of creation of the land-use planning regulations 
Table 1 Area Socioeconomic status, Walkability and neighborhood dynamics indicators

\begin{tabular}{|c|c|c|c|c|c|}
\hline Construct & Domain & Indicator & Operationalization & Source & Level \\
\hline \multirow[t]{7}{*}{ SES } & \multirow[t]{2}{*}{ Education } & Low Education & $\begin{array}{l}\text { Residents with mandatory studies } \\
\text { or below/all residents aged } 25 \text { or above }\end{array}$ & Padron & Census section \\
\hline & & High Education & $\begin{array}{l}\text { Residents with university education } \\
\text { or above/all residents aged } 25 \text { or above }\end{array}$ & Padron & Census section \\
\hline & \multirow[t]{3}{*}{ Occupation } & Part time Jobs & Workers in part-time jobs/all workers & \multirow[t]{3}{*}{ Social security } & \multirow[t]{3}{*}{ Neighborhood } \\
\hline & & Temporal Jobs & Workers in temporal jobs/all workers & & \\
\hline & & Manual Occupation Class & $\begin{array}{l}\text { Workers in manual or unskilled } \\
\text { occupations/all workers }\end{array}$ & & \\
\hline & Wealth & Housing Prices & Average sale price of housing per $\mathrm{m}^{2}$ & Idealista report & Census section \\
\hline & Living Conditions & Unemployment Rate & $\begin{array}{l}\text { Residents registered as unemployed/ } \\
\text { all residents aged 16-64 }\end{array}$ & $\begin{array}{l}\text { Employment } \\
\text { service }\end{array}$ & Neighborhood \\
\hline \multirow[t]{4}{*}{ Walkability } & Density & Residential Density & Occupied Dwellings $/ \mathrm{km}^{2}$ & $\begin{array}{l}\text { Housing } \\
\text { census }\end{array}$ & Census section \\
\hline & Density & Population Density & Residents $/ \mathrm{km}^{2}$ & Padron & Census section \\
\hline & Destinations & Retail Destinations & Retail and Service Destinations $/ \mathrm{km}^{2}$ & $\begin{array}{l}\text { Retail spaces } \\
\text { census }\end{array}$ & Census section \\
\hline & Street Structure & Street Connectivity & $\begin{array}{l}\text { Kernel Density in } 3 \mathrm{~m} \times 3 \mathrm{~m} \text { pixels of the density } \\
\text { of street intersections }\end{array}$ & CARTOCIUDAD & Census section \\
\hline \multirow[t]{2}{*}{$\begin{array}{l}\text { Neighborhood } \\
\text { dynamics }\end{array}$} & Gentrification & Increase in Education level & $\begin{array}{l}\text { Rank difference in high education from } 2005 \\
\text { to } 2014 \text { (>p95) }\end{array}$ & Padron & Census section \\
\hline & Neighborhood age & Year of construction & Median year of construction (categorized) & Catastro & Census section \\
\hline
\end{tabular}

of the city [34]. Table 1 (and Additional file 1) contains more details on the operationalization of indicators.

\section{Walkability}

A walkability index for the 2415 census sections was created, reflecting known barriers and promoters to walking behaviors [9]. The core components of walkability indexes are the presence of places to walk to, a street network that facilitates such walking and enough density to guarantee that destinations are not too far apart [9]. Based on these, many previous measures of walkability have been developed [35]. Here, we used an index based on work by Creatore et al. [36] with modifications based on European recommendations [37]. The following indicators were used: Residential Density (occupied dwellings/ $\mathrm{km}^{2}$ ), Population Density (Residents $/ \mathrm{km}^{2}$ ), Retail Destinations (Retail and services destinations $/ \mathrm{km}^{2}$ ) and Street Connectivity (Kernel Density in $3 \mathrm{~m} \times 3 \mathrm{~m}$ pixels of the density of street intersections). Data were obtained from the Housing part of the Spanish Census (that includes data on occupied dwellings), the Padrón (sociodemographic data), the Retail Spaces Census (curated by the local government for licensing purposes, that includes data on economic activities of all occupied commercial spaces) and CARTOCIUDAD (the National Mapping Agency initiative that collects and makes available official geo-referenced urban data, including street structure and administrative boundaries in shapefile format). All data were available for 2014 except for the Spanish Census, available for 2011. Table 1 (and Additional file 1) contains more details on the operationalization of indicators. To create the walkability index, we followed the same procedure as for the exposure (see above), and weighted the four indicators equally.

\section{Statistical analysis}

The objective of this analysis was to study the association between area-level socioeconomic status and area-level walkability, and how neighborhood dynamics influence these associations. We conducted exploratory and descriptive analysis of the exposure and the outcome variables, by tertile of neighborhood SES (Additional file 2: Table S2). We also plotted the distribution of SES and walkability indexes and examined their association using a non-parametric lowess [38] estimator, to provide an idea of the best operationalization of the neighborhood SES indicator.

To study the association between neighborhood SES and walkability we used linear mixed models with the walkability index as the dependent variable. These models included a random intercept for neighborhood (as census sections are nested into neighborhoods). We assessed whether a third level (for district) was needed by adding a random intercept for district and performing a likelihood ratio test of the nested models. Afterwards, we further included the SES Index operationalized as deciles, with the sixth decile as the reference. Based on the exploratory analysis above, we also conducted an analysis where 
we modeled the association using restricted cubic splines with 5 knots placed in the percentiles recommended by Harrell [39]. The number of knots was decided after testing 3-6 knots models and selecting the best fitting model based on Akaike Information Criterion (AIC).

We tested for effect modification by neighborhood dynamics indicators by adding an interaction term between the gentrification or neighborhood age indicator(s) and each restricted cubic spline. We checked for the significance of this interaction by conducting a likelihood ratio test in nested models with and without the interaction. All analyses were conducted using Stata SE version 14.1 (StataCorp., College Station, TX, USA).

\section{Results}

\section{Spatial distribution of SES and walkability}

The spatial distribution of SES and walkability indexes is shown in Fig. 1. Walkability was higher in the downtown area of Madrid (inside the M-30 orbital motorway of Madrid). There are also some pockets of high walkability in the areas adjacent to the M-30 orbital motorway, especially in the Southeastern and Southwestern parts of the city. Socioeconomic status followed a major
North-South decreasing gradient (higher SES in the Northern areas of the city), while the Southern peripheral neighborhoods of the city had a lower SES.

\section{Association between SES and walkability}

Table 2 shows the main results of the study, obtained from a three-level mixed effects model. All SES Index deciles showed statistical significant differences compared to the reference group (sixth decile). Lower SES census sections had the highest walkability: there was an increase of $2.19 \mathrm{SD}$ (CI 95\% 1.36; $3.01 \mathrm{p}<0.001)$ ) $2.87 \mathrm{SD}$ (CI 95\% 2.19; 3.54 p < 0.001) and 2.02 SD (CI 95\% 1.46; $2.59 \mathrm{p}<0.001)$ of walkability in the first, second and third decile of SES respect to the reference group. Fourth and fifth SES-deciles also ranked higher in walkability than the reference. Higher SES deciles had lower walkability: there was a decrease in walkability of 2.93 SD (CI 95\% $-3.60 ;-2.26 \mathrm{p}<0.001)$ and $3.86 \mathrm{SD}(\mathrm{CI} 95 \%-4.61$; $-3.12 \mathrm{p}<0.001)$ for the ninth and tenth SES-deciles.

Figure 2 shows the results of the model using restricted cubic splines with 5 knots. This figure shows a doseresponse association for most of the SES distribution, with the only exception of a slight change in the

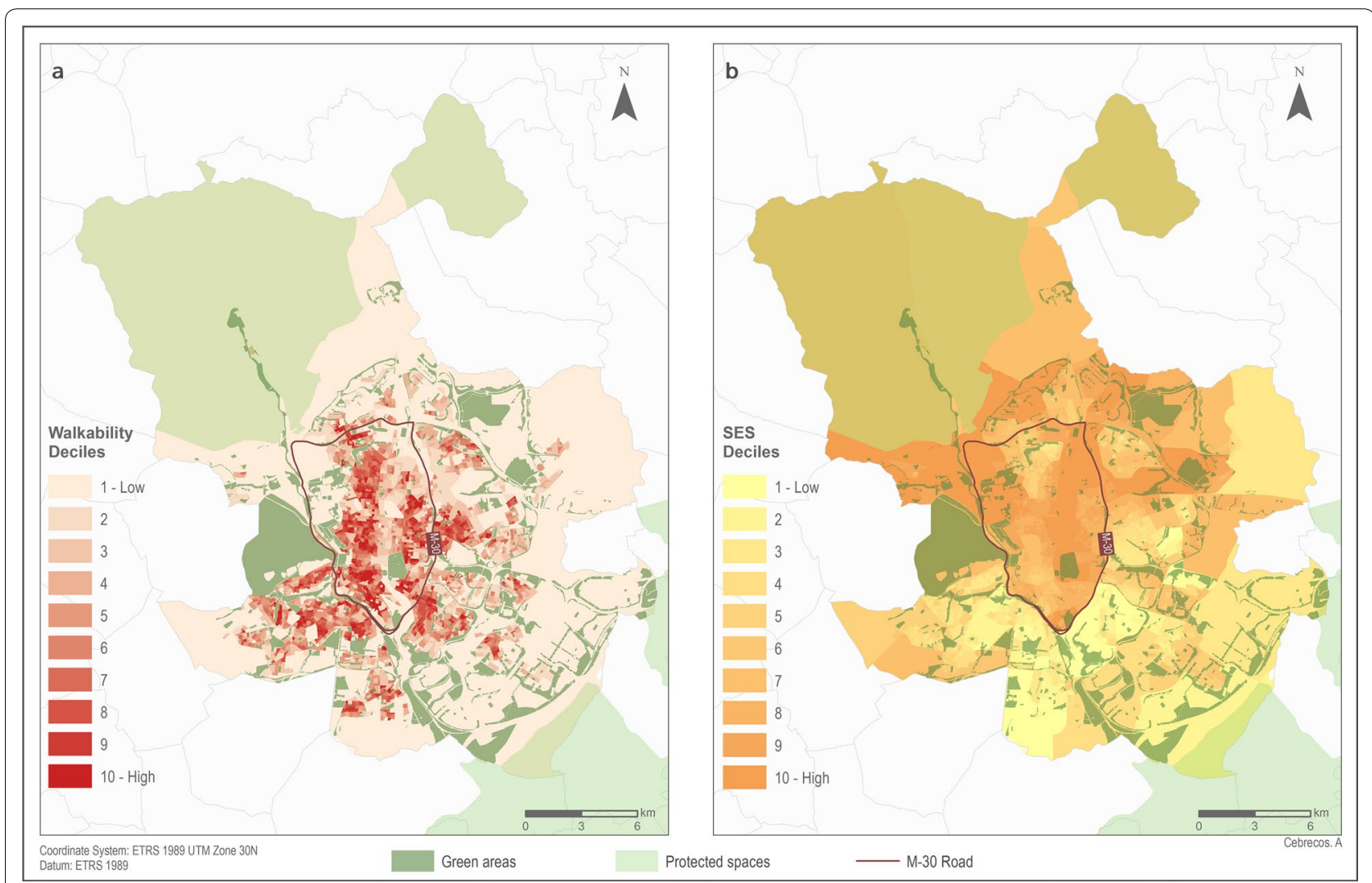

Fig. 1 Spatial distribution of Walkability Index (a) and Socio-Economic Status Index (b) by deciles in the census section $(N=2415)$ of the city of Madrid 
Table 2 Results from multilevel regression analysis between area SES Index and walkability Index ( $N=2415$ census sections)

\begin{tabular}{llll}
\hline SES Index decile & $\boldsymbol{\beta}$ & $\mathbf{9 5 \%} \mathbf{C l}$ & $\mathbf{p ~ v a l u e}$ \\
\hline 1 & 2.19 & $1.36 ; 3.01$ & $<0.001$ \\
2 & 2.87 & $2.19 ; 3.54$ & $<0.001$ \\
3 & 2.02 & $1.46 ; 2.59$ & $<0.001$ \\
4 & 1.26 & $0.73 ; 1.80$ & $<0.001$ \\
5 & 0.53 & $0.06 ; 0.99$ & 0.027 \\
6 & & Ref & \\
7 & -1.65 & $-2.17 ;-1.13$ & $<0.001$ \\
8 & -2.23 & $-2.85 ;-1.61$ & $<0.001$ \\
9 & -2.93 & $-3.60 ;-2.26$ & $<0.001$ \\
10 & -3.86 & $-4.61 ;-3.12$ & $<0.001$ \\
\hline
\end{tabular}

association in the lowest tail of SES, where walkability decreases as SES decreases.

\section{Interaction by neighborhood dynamics}

Figure 3 shows the results of the interaction with neighborhood dynamics. Panel A shows the analysis by change in education level (gentrification), where we found a significant interaction between SES and change in education level $(\mathrm{p}<0.001)$ : while areas with stable or decreasing education level showed the same overall pattern (decrease in walkability with increasing SES), areas that increased its education level had a flat pattern with no association between neighborhood SES and walkability. Panel B show the analysis by neighborhood age, where we also found a significant interaction $(\mathrm{p}<0.001)$. The association was similar in shape for areas built before 1985 and between 1985 and 1997 (albeit these second group showed an overall decrease in walkability regardless of SES). Areas built after 1997 showed a flat association, with no decrease in walkability in areas with higher SES.

\section{Discussion}

Our results indicate that census sections with higher socioeconomic status had a less walkable-urban form, as defined by our Walkability Index. This association followed, for the most part, a dose-response linear pattern. Moreover, we found that this association is heterogeneous, as there are significant interactions by a marker of gentrification and neighborhood age.

The negative association between area SES and walkability has been found in other studies $[16-19,21]$. For

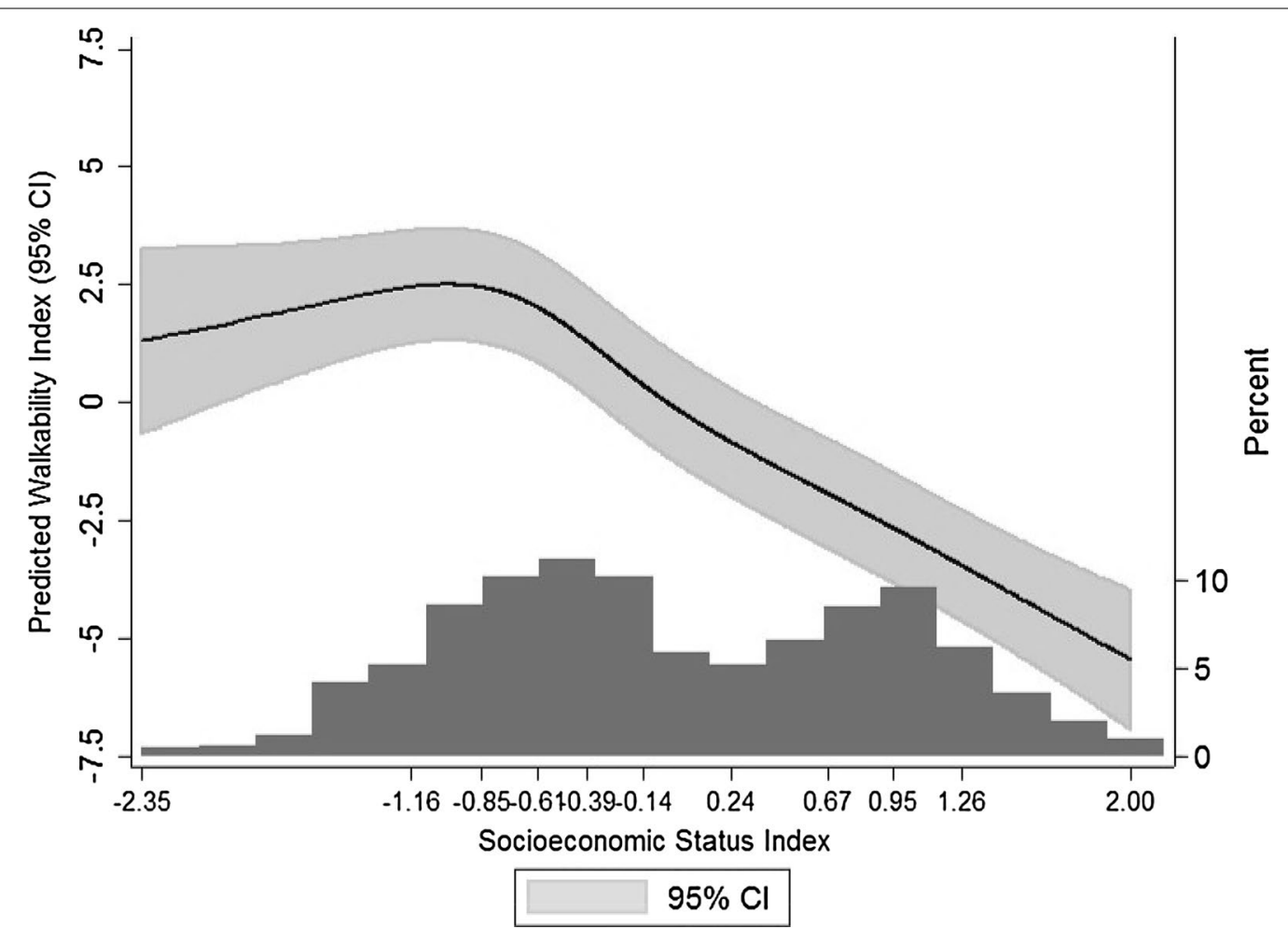

Fig. 2 Restricted cubic splines with 5 knots placed in the percentiles recommended by Harrell [39] showing the relationship between SES and walkability indexes in all Madrid census sections $(\mathrm{N}=2415)$. $X$ axis represents the min, max and 10 deciles of the SES Index, and $Y$ axis represents the predicted Walkability Index. The line represents the predicted walkability through SES level and its 95\% Cl. Histogram represents the SES Index distribution of the 2415 census sections 

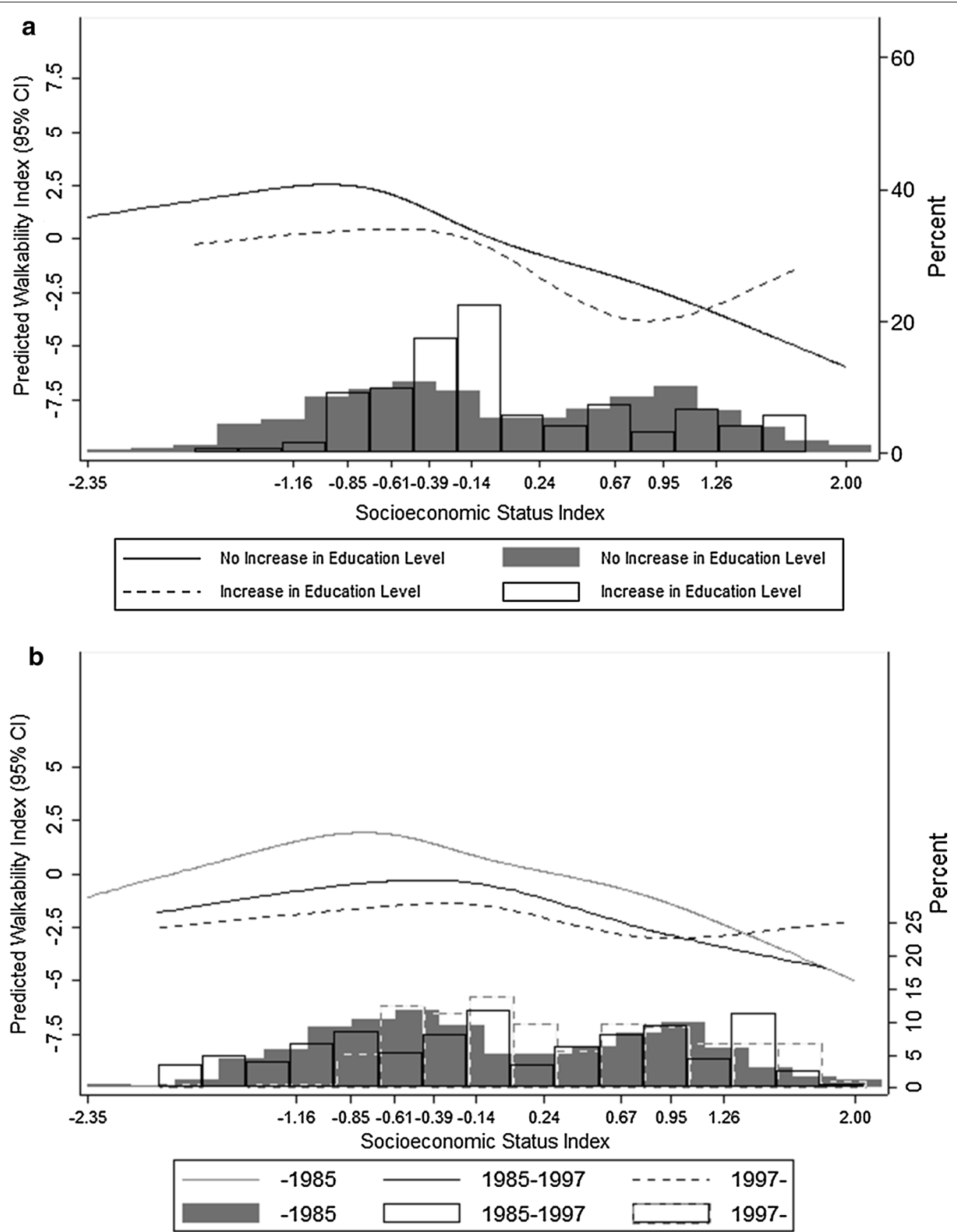

Fig. 3 Interaction effect by indicators of neighborhood dynamics (a gentrification, b neighborhood age) using restricted cubic splines with 5 knots placed in the percentiles recommended by Harrell [39]

example, Carpenter et al. [19] found a positive relationship between street connectivity and neighborhood poverty. King et al. [16] found that disadvantaged neighborhoods in terms of median income were more walkable (shorter block length, greater street node density, more developed land use, and higher density of street segments); on the other hand, they also found that more educated neighborhoods were also more walkable [16]. In our study, we created a composite Index, which allow us to better measure SES by using information from several indicators and therefore reduce the degree of measurement error. Other studies found that residents of more deprived neighborhoods report worst aesthetics and safety of their neighborhoods [20, 21]. Mixed-methods 
between quantitative and qualitative methods [40] could represent an alternative in order to understand the different associations between objective and subjective walkability measures.

We found an interaction with our marker of gentrification (top 95\% percentile of rank change in high-education level in the last 10 years). Non-gentrified areas showed an inverse association between SES and walkability, while gentrified areas show a flat association between SES and walkability. As opposed to non-gentrified areas, where a "disadvantage" [16] in walkability was evident for higher-SES census sections, this phenomenon was not present in gentrified areas where higher-SES census sections had a similar walkability as lower SES ones. One potential explanation for this phenomenon is an increasing popularity of walkable neighborhoods (reflected by the increase of housing prices), where lower-SES residents are not able to continue living due to a decrease in affordable housing, causing a replacement of lower-SES residents for higher SES residents [25]. These gentrification and urban renewal processes have launched popular movements and social mobilization against them [41].

We also found an interaction by neighborhood age (assessed by our indicator of median year of building construction). The newest areas (those with its median year of construction after 1997) had a flat curve compared with the older neighborhoods (built before 1997). Independent of SES, historic and old neighborhoods tend to have a greater walkability due mostly to a denser street network [42]. Similarly to our gentrification analysis, there is a lack of a walkability disadvantage in higher SES areas built from 1997 onwards. Conversely, there is a lack of an "advantage' in walkability in lower SES areas, probably reflecting the newer developments of lower SES housing in the periphery of Madrid, with a less dense street network and lower availability of destinations. Recent research has shown an initiation of sprawling patterns in Mediterranean cities the last decades [43].

This study has several strengths. First, as far as we know, this is the first study to explore the walkability-SES association in an Southern European setting, characterized by its overall higher density [22], and to look at what is the effect that social and urban form dynamics have on it. We have also built a strong SES and walkability measures using GIS and an integrated composite index, which allow us to better measure SES by using information from several indicators and therefore reduce the degree of measurement error. Our walkability Index has been adapted for one used in Canada [36], but the changes followed some adaptations that could be needed for European context, using different measures for connectivity and land-use [37]. Most of the walkability literature has been conducted in the US, Canada and Australia or New
Zealand, in cities with a much shorter lifespan than European cities [9]. We believe that conducting this type of research in European cities with a longer historical trajectory, a presence of different urban form structures (like historical mixed-use downtown areas) provides a different mechanistic insight into the determinants of walkability and can help inform policies in European cities in a more appropriate way.

This study has some limitations. We only measure the association of area-SES with walkability, a very specific set of features that promote walking behaviors, and may be missing another physical activity environment measures which could be important for public health, such as perception of crime and safety which are important determinants specially in low SES areas [21]. We were not able to link our data to individual-level health behavior (e.g. walking) or outcome (e.g. obesity) data, which could give us a better understanding on the effects of walkability in shaping health inequities. Our marker of gentrification is an unspecific one, as a change in education proportions may reflect both residential mobility phenomena (linked to gentrification) and changes in the non-moving population (linked to social mobility). Further research in Madrid with residential mobility data should explore the impact of these two phenomena on our inferences.

Our study supports the idea that low-income neighborhoods had a more-walkable urban form; however, neighborhood dynamics in terms of social composition (gentrified neighborhood) and in terms of neighborhood age (newest areas) did not follow the same pattern. These findings are key to understand how to address physical activity inequities within a city. If new neighborhoods in Madrid are built following a different socio-spatial distribution of walkability (more favorable for the wealthy, or with a loss of a walkability advantage for the poor), and the wealthy people are moving to the walkable neighborhoods [25], there is a need to balance with safeguards to preserve affordability and avoid the displacement of low-SES populations, keeping the "right to the city" with adequate housing reforms [44]. Therefore, continued attention needs to be paid to equity in urban policies to change the urban form to ensure changes do not have the unintended consequence of increased health inequities [45].

\section{Conclusions}

In conclusion, our study shows that higher SES areas of Madrid had lower walkability compared with lower SES areas. However, neighborhood dynamics in terms of social (gentrification) an urban form (neighborhood age) modified this association; newest and gentrified neighborhoods had a flat curve between area-SES and 
walkability. A deeper understanding of the dynamic relationship between urban form and neighborhood composition would provide further insights into mobility and health behaviors and outcomes, and inform urban planning policy in European cities to preserve health equities.

\section{Additional files}

Additional file 1: Additional information on the operationalization of the variables.

Additional file 2. Table S2: Census section sociodemographic and walkability indicators according to socioeconomic status (SES) tertiles (N $=2415$.

\section{Authors' contributions}

MF and PG conceived the idea. PG and UB conceptualized and designed the study, conducted data collection and data managing and performed all statistical analyses. AC obtained the GIS data and mapped all results. PG, UB and MF wrote the first draft of the manuscript. All authors read and approved the final manuscript.

\footnotetext{
Author details

1 Social and Cardiovascular Epidemiology Research Group, School of Medicine, University of Alcalá, Alcalá de Henares, Madrid 28871, Spain. ${ }^{2}$ Escuela Nacional de Sanidad, Instituto de Salud Carlos III, Madrid 28029, Spain. ${ }^{3}$ Department of Epidemiology, Johns Hopkins Bloomberg School of Public Health, Baltimore 21205, MD, USA. ${ }^{4}$ Department of Geology, Geography and Environmental Sciences, University of Alcalá, Alcalá de Henares, Madrid 28871, Spain. ${ }^{5}$ Center for Urban Research, RMIT University, Melbourne 3000, VIC, Australia.

${ }^{6}$ Centro Nacional de Epidemiología, Instituto de Salud Carlos III, Madrid 28029, Spain.
}

\section{Acknowledgements}

The authors we would like to thank the whole Social and Cardiovascular Epidemiology Research Group at University of Alcalá, for its collaboration, ideas and feedback during the whole process of this study.

\section{Competing interests}

The authors declare that they have no competing interests.

\section{Funding}

This study was supported by the European Research Council under the European Union's Seventh Framework Programme (FP/2007-2013)/ERC Starting Grant HeartHealthyHoods Agreement n. 336893. PG was supported by Enrique Nájera grant for Young Epidemiologists (12th edition) awarded by the Sociedad Española. UB was supported by a fellowship from the Obra Social La Caixa and by a Johns Hopkins Center for a Livable Future-Lerner Fellowship. HB was in part supported by VicHealth, the National Health and Medical Research Council (NHMRC) Centre of Research Excellence in Healthy, Liveable Communities (\#1061404), and The Australian Prevention Partnership Centre (\#9100001), with funding provided by NHMRC, ACT Health, NSW Health, the Australian National Preventive Health Agency, the Hospitals' Contribution Fund of Australia, and the HCF Research Foundation.

\section{Publisher's Note}

Springer Nature remains neutral with regard to jurisdictional claims in published maps and institutional affiliations.

Received: 10 January 2017 Accepted: 31 May 2017

Published online: 06 June 2017

\section{References}

1. Gerovasili V, Agaku IT, Vardavas Cl, Filippidis FT. Levels of physical activity among adults 18-64 years old in 28 European countries. Prev Med. 2015;81:87-91. doi:10.1016/j.ypmed.2015.08.005.

2. WHO. Global status report on noncommunicable diseases 2014 [Internet]. World Health Organization. 2014. http://www.who.int/topics/ cardiovascular_diseases/en/.

3. Lee I, Shiroma EJ, Lobelo F, Puska P, Blair SN, Katzmarzyk PT, et al. Effect of physical inactivity on major non-communicable diseases worldwide: an analysis of burden of disease and. Lancet. 2012;380:219-29. doi:10.1016/ S0140-6736(12)61031-9.

4. Rose G. sick individuals and sick populations GEOFFREY ROSE. Int J Epidemiol. 1985;14:32-8.

5. Benach J, Malmusi D, Yasui Y, Martínez JM. A new typology of policies to tackle health inequalities and scenarios of impact based on Rose's population approach. J Epidemiol Community Health. 2013;67:286-91. http://www.jech.bmj.com/content/67/3/286.abstract\%5Cnhttp://jech. bmj.com/content/67/3/286.full.pdf.

6. Franco M, Bilal U, Diez-Roux A-V. Preventing non-communicable diseases through structural changes in urban environments. J Epidemiol Community Health. 2014;69:509-11. doi:10.1136/jech-2014-203865.

7. Diez Roux A-V. Neighborhoods and health: where are we and were do we go from here? Rev Epidemiol Sante Publique. 2007;55:13-21. http:// linkinghub.elsevier.com/retrieve/pii/S0398762006000046.

8. Sallis JF, Cerin E, Conway TL, Adams MA, Frank LD, Pratt M, et al. Physical activity in relation to urban environments in 14 cities worldwide: a crosssectional study. Lancet. 2016;387:2207-17.

9. Hajna S, Ross NA, Brazeau A-S, Bélisle P, Joseph L, Dasgupta K. Associations between neighbourhood walkability and daily steps in adults: a systematic review and meta-analysis. BMC Public Health. 2015;15:768. http://www.biomedcentral.com/1471-2458/15/768.

10. Ferdinand AO, Sen B, Rahurkar S, Engler S, Menachemi N. The relationship between built environments and physical activity: a systematic review. Am J Public Health. 2012;102:7-13.

11. Farrell L, Hollingsworth B, Propper C, Shields MA. The socioeconomic gradient in physical inactivity: evidence from one million adults in England. Soc Sci Med. 2014;123:55-63. doi:10.1016/j.socscimed.2014.10.039.

12. Beenackers MA, Kamphuis CBM, Giskes K, Brug J, Kunst AE, Burdorf A, et al. Socioeconomic inequalities in occupational, leisure-time, and transport related physical activity among European adults: a systematic review. Int J Behav Nutr Phys Act. 2012;9:116. http://www.scopus.com/ inward/record.url?eid=2-s2.0-84866279745\&partnerlD=tZOt×3y1.

13. Pascual C, Regidor E, Alvarez-Del Arco D, Alejos B, Santos JM, Calle ME, et al. Sports facilities in Madrid explain the relationship between neighbourhood economic context and physical inactivity in older people, but not in younger adults: a case study. J Epidemiol Community Health. 2013;67:788-94.

14. Huang J, Lu XX, Sellers JM. A global comparative analysis of urban form: applying spatial metrics and remote sensing. Landsc Urban Plan. 2007:82:184-97.

15. Turrell G, Haynes M, Wilson LA, Giles-Corti B. Can the built environment reduce health inequalities? A study of neighbourhood socioeconomic disadvantage and walking for transport. Health Place. 2013;19:89-98. doi:10.1016/j.healthplace.2012.10.008.

16. King KE, Clarke PJ. A disadvantaged advantage in walkability: findings from socioeconomic and geographical analysis of national built environment data in the United States. Am J Epidemiol. 2015;181:17-25.

17. Thornton CM, Conway TL, Cain KL, Gavand KA, Saelens BE, Frank LD, et al. Disparities in pedestrian streetscape environments by income and race/ethnicity. SSM Popul Health. 2016;2:206-16. doi:10.1016/j. ssmph.2016.03.004.

18. Zhu X, Lee C. Walkability and safety around elementary schools. economic and ethnic disparities. Am J Prev Med. 2008;34:282-90.

19. Carpenter A, Peponis J. Poverty and connectitvity. J Sp Syntax. 2010;1:108-20. http://128.40.150.106/joss/index.php/joss/article/ viewFile/23/pdf 10. 
20. Sallis JF, Slymen DJ, Conway TL, Frank LD, Saelens BE, Cain K, et al. Income disparities in perceived neighborhood built and social environment attributes. Health Place. 2011;17:1274-83. doi:10.1016/j. healthplace.2011.02.006.

21. Sugiyama T, Howard NJ, Paquet C, Coffee NT, Taylor AW, Daniel M. Do relationships between environmental attributes and recreational walking vary according to area-level socioeconomic status? J Urban Health. 2015;92:253-64.

22. Kazepov Y. Cities of Europe: changing contexts, local arrangement and the challenge to urban cohesion. Oxford: Wiley; 2005.

23. Musterd S. Social and ethnic segregation in Europe: levels, causes, and effects. J Urban Aff. 2005;27:331-48.

24. van Ham M, Manley D, Bailey N, Simpson L, Maclennan D, editors. Understanding neighbourhood dynamics. Dordrecht: Springer; 2013. doi:10.1007/978-94-007-4854-5.

25. Koschinsky J, Talen E. Affordable housing and walkable neighborhoods: a national urban analysis. Cityscape A J Policy Dev Res. 2015;17:13-56.

26. Bilal U, Díez J, Alfayate S, Gullón P, Del Cura I, Escobar F, et al. Population cardiovascular health and urban environments: the Heart Healthy Hoods exploratory study in Madrid, Spain. BMC Med Res Methodol. 2016;16:104. http://www.ncbi.nlm.nih.gov/pubmed/27549991.

27. Carreño V, Franco M, Gullón P, Carreño V. Studying city life, improving population health. Int J Epidemiol. 2015; doi:10.1093/ije/dyv207.

28. Gullón P, Badland HM, Alfayate S, Bilal U, Escobar F, Cebrecos A, et al. Assessing walking and cycling environments in the streets of madrid: comparing on-field and virtual audits. J Urban Health. 2015;92:923-39. http://www.ncbi.nlm.nih.gov/pubmed/26349472.

29. INE. Estadísticas del padrón continuo 2014. Madrid; 2014. http://www.ine es/jaxi/menu.do?type $=$ pcaxis\&path $=/$ t20/e245/\&file $=$ inebase

30. Leal J, Sorando D. Economic crisis, social change and segregation processes in Madrid. Socioecon Segreg Eur Cap Cities East Meets West. 2016;214-37.

31. Gago García C, Serrano Cambronero M, Antón Burgos FJ. Repercusiones de las carreteras orbitales de la Comunidad de Madrid en los cambios de usos del suelo. Ann Geogr. 2004;145-67. http://cat.inist.fr/?aModele=affic heN\&cpsidt $=17632244$

32. Ministerio de Sanidad Servicios Sociales e Igualdad. Avanzando hacia la equidad. Propuesta de políticas e intervenciones para reducir las desigualdades sociales en salud en España. 2015;17-23. http://www. mspsi.gob.es/profesionales/saludPublica/prevPromocion/promocion/ desigualdadSalud/docs/Propuesta_Politicas_Reducir_Desigualdades.pdf.
33. Borrell C, Malmusi D, Muntaner C. Introduction to the "Evaluating the Impact of Structural Policies on Health Inequalities and Their Social Determinants and Fostering Change" (SOPHIE) Project. Int J Health Serv. 2017:47:10-7. doi:10.1177/0020731416681891.

34. González Pérez JM. Urban planning system in contemporary Spain. Eur Plan Stud. 2007;15:29-50.

35. Feng J, Glass TA, Curriero FC, Stewart WF, Schwartz BS. The built environment and obesity: a systematic review of the epidemiologic evidence. Health Place. 2010;16:175-90. doi:10.1016/j.healthplace.2009.09.008.

36. Creatore MI, Glazier RH, Moineddin R, Fazli GS, Johns A, Gozdyra P, et al. Association of neighborhood walkability with change in overweight, obesity, and diabetes. JAMA 2016;315:2211. http://jama.jamanetwork. com/article.aspx?doi=10.1001/jama.2016.5898.

37. Grasser G, van Dyck D, Titze S, Stronegger WJ. A European perspective on GIS-based walkability and active modes of transport. Eur J Public Health. 2016: doi:10.1093/eurpub/ckw118.

38. Cleveland WS, Devlin SJ. Locally weighted regression: an approach to regression analysis by local fitting. J Am Stat Assoc. 1988;83:596-610. doi: 10.1080/01621459.1988.10478639

39. Harrell FE. Regression modeling strategies. Cham: Springer International Publishing; 2015. doi:10.1007/978-3-319-19425-7.

40. Meissner H, Creswell J, Klassen AC, Plano V, Smith KC. Best practices for mixed methods research in the health sciences. Bethesda: National Institutes of Health; 2011.

41. Díaz Orueta F. Madrid: urban regeneration projects and social mobilization. Cities. 2007;24:183-93.

42. Friedman B, Gordon SP, Peers JB. Effect of neotraditional neighborhood design on travel characteristics. Transp Res Rec. 1994;63-70. http://trid. trb.org/view.aspx?id=425323.

43. Munoz F. Lock living: urban sprawl in mediterranean cities. Cities. 2003;20:381-5

44. Kadi J, Ronald R. Market-based housing reforms and the "right to the city": the variegated experiences of New York, Amsterdam and Tokyo. Int J Hous Policy. 2014;14:268-92. doi:10.1080/14616718.2014.928098.

45. Hirsch JA, Grengs J, Schulz A, Adar SD, Rodriguez DA, Brines SJ, et al. How much are built environments changing, and where?: patterns of change by neighborhood sociodemographic characteristics across seven US metropolitan areas. Soc Sci Med. 2016;169:97-105. doi:10.1016/j. socscimed.2016.09.032.

\section{Submit your next manuscript to BioMed Central and we will help you at every step:}

- We accept pre-submission inquiries

- Our selector tool helps you to find the most relevant journal

- We provide round the clock customer support

- Convenient online submission

- Thorough peer review

- Inclusion in PubMed and all major indexing services

- Maximum visibility for your research

Submit your manuscript at www.biomedcentral.com/submit
BioMed Central 